\title{
OS FATORES QUE INFLUENCIAM OS EGRESSOS DO CURSO DE SECRETARIADO EXECUTIVO TRILÍNGUE DA UNIVERSIDADE FEDERAL DE VIÇOSA A INGRESSAREM NO SERVIÇO PÚBLICO
}

THE FACTORS THAT INFLUENCE THE EXECUTIVE SECRETARIAT UNDERGRADUATES FROM UNIVERSIDADE FEDERAL DE VIÇOSA TO WORK AT THE PUBLIC SECTOR

\section{Emilia de Oliveira Faria}

Graduada em Secretariado Executivo pela Universidade Federal de Viçosa - UFV Secretária Executiva da Universidade de Brasília - UnB E-mail: emiliaofaria@gmail.com (Brasil)

\section{Tatiana Rodrigues Silveira}

Graduada em Secretariado Executivo pela Universidade Federal de Viçosa - UFV Analista da Empresa Brasileira de Pesquisa Agropecuária

E-mail: tatiana.rodriguessilveira@gmail.com (Brasil) 


\title{
OS FATORES QUE INFLUENCIAM OS EGRESSOS DO CURSO DE SECRETARIADO \\ EXECUTIVO TRILÍNGUE DA UNIVERSIDADE FEDERAL DE VIÇOSA A \\ INGRESSAREM NO SERVIÇO PÚBLICO
}

\begin{abstract}
RESUMO
As oportunidades de trabalho no setor público têm interessado um número crescente de indivíduos que optam por esse caminho em busca de estabilidade, qualidade de vida, oportunidade de construir uma carreira, treinamento e benefícios, entre outras vantagens oferecidas. Algumas razões são sugeridas para a busca do emprego público: elevação nas taxas de desemprego no setor privado; menor discriminação no processo seletivo quanto à idade, ao sexo e à universidade de formação; não exigência de experiência prévia ou critérios estereotipados, tais como boa aparência, entre outros. O objetivo desse estudo foi o de identificar as preferências e fatores que motivaram os estudantes de Secretariado Executivo Trilíngue da Universidade Federal de Viçosa a optar pelo serviço público, especificamente, nas IFES (Instituições Federais de Ensino Superior). A tendência nas respostas dadas à maioria das questões mostra que os aspectos "estabilidade" e segurança foram os fatores mais indicados como motivadores para ingressar em uma estatal.
\end{abstract}

Palavras-chave: Setor Público; Mercado de Trabalho; Teorias Motivacionais.

\author{
THE FACTORS THAT INFLUENCE THE EXECUTIVE SECRETARIAT \\ UNDERGRADUATES FROM UNIVERSIDADE FEDERAL DE VIÇOSA TO WORK AT \\ THE PUBLIC SECTOR
}

\begin{abstract}
The work opportunities in the public sector are starting to interest an increasing number of individuals who expect to find in these sort of companies stability, quality of life, opportunities to build a career, training and benefits, among other advantages. Some reasons for the interest in public jobs are suggested: increasing rates of unemployment in private sector; less discrimination in recruitment process concerning age, gender, university; no request of previous experience or conventional criteria. The present study is aimed to identifying the preferences and factors that motivate the Executive Secretariat students from Universidade Federal de Viçosa who have opted for an employment in the public sector, specifically in a Federal Undergraduate Educational Institution (IFES in Portuguese). The tendency of the answers to most of the questions revealed that aspects as stability and security were the most highlighted factors as motivators to joining a public company.
\end{abstract}

Keywords: Public Sector; Labor Market; Motivational Theory.

Revista de Gestão e Secretariado - GeSec, São Paulo, v. 6, n. 1, p 48-73, jan./abr. 2015. 


\section{INTRODUÇÃO}

A conclusão de um curso universitário significa a promessa de nova fase de vida para muitos jovens - fase esta caracterizada pela inserção no mercado de trabalho. Entretanto, um dos principais problemas com os quais os recém-formados se deparam é a dificuldade de ingressar em suas profissões. Nesse cenário de enorme concorrência, no qual só o diploma já não é mais garantia de uma boa colocação ou de um emprego bem remunerado, exige-se do futuro profissional a busca por diversas alternativas.

Nesse contexto, milhares de pessoas, vêm procurando cada vez mais o ingresso no serviço público. No final do século XX, a carreira no serviço público era vista como uma opção para aquelas pessoas que procuravam um ambiente sem desafios e ou que não obtinham êxito na iniciativa privada. A imagem do funcionário público era vinculada a um baixo nível de eficiência. Além disso, acreditava-se que a carreira pública oferecia poucas perspectivas de crescimento, baixos salários e poucos benefícios.

Essa visão do funcionalismo público vem sofrendo consideráveis modificações. O serviço público surge no contexto atual como uma alternativa diante das constantes turbulências econômicas que, por sua vez, influenciam diretamente o setor privado.

É importante enfatizar que a elevação nas taxas de desemprego e instabilidade econômica não são os únicos fatores que justificam a escolha da carreira pública. Algumas razões têm sido levantadas para a busca pelo emprego público, como: menor discriminação no processo seletivo quanto à idade, sexo, universidade de formação, entre outros; não exigência de experiência prévia ou critérios estereotipados, tal como boa aparência; mudança na política de desenvolvimento de pessoal das empresas públicas, que passaram a realizar mais investimentos em capacitação profissional.

Dados levantados junto à coordenação do curso de Secretariado Executivo Trilíngue da UFV demonstram que seus estudantes seguem essa tendência mercadológica. Tendo em vista as informações supracitadas, surgiu o interesse em estudar mais profundamente quais seriam as motivações individuais que levam o egresso de SET da Universidade Federal de Viçosa a optar pelo serviço público.

O escopo do trabalho foi organizado em quatro seções. A seção 2 constituiu o arcabouço teórico que embasou esta pesquisa dividida da seguinte maneira: histórico do conceito de trabalho; o mercado de trabalho atual e escolha profissional; as teorias motivacionais, mais especificamente a Teoria da autodeterminação; a administração pública brasileira. Na terceira seção, foram 
apresentados os pressupostos metodológicos seguidos dos aspectos técnicos e dos procedimentos para coleta e análise dos dados. Em seguida, na seção 4, foram apresentados os dados coletados e seus desdobramentos. Por fim, a quinta seção contemplou considerações finais e sugestões para novos estudos.

\section{REFERENCIAL TEÓRICO}

Os aspectos centrais deste trabalho pautam-se na visão que o egresso do Curso de Secretariado Executivo Trilíngue da UFV tem do mercado de trabalho e suas escolhas. Dessa forma, serão apresentadas algumas concepções que servirão de base para um entendimento mais acurado da realidade do profissional da área.

\subsection{SIGNIFICADO DE TRABALHO}

Bastos, Pinho e Costa (1995) levantam uma discussão acerca do uso do termo trabalho. Eles apontam dois grandes eixos de significados com componentes avaliativos claramente antagônicos. O primeiro eixo vincula ao trabalho, a noção de sacrifício, de carga, fardo. Segundo tais autores, nesse eixo, o trabalho associa-se ao termo punição. Essa vertente traz uma avaliação negativa do trabalho e está diretamente relacionado ao significado do termo trabalho em latim, tripalium, instrumento de tortura.

Ainda na concepção de Bastos et al. (1995), o segundo eixo vê o trabalho como a aplicação das capacidades humanas para propiciar o domínio da natureza, sendo responsável pela própria condição humana. Esse conceito está ligado à noção de empenho e esforço para atingir determinado objetivo.

De acordo com Borges e Tamayo (2010), o significado do trabalho varia individualmente, na medida em que deriva do processo de atribuir significados e apresenta, simultaneamente, aspectos socialmente compartilhados, associados às condições históricas da sociedade. É, portanto, constructo sempre inacabado. Corroborando essa concepção, Albornoz (1994) afirma que "as razões para trabalhar estão no próprio trabalho e não fora dele ou em qualquer de suas consequências". 


\subsubsection{MERCADO DE TRABALHO}

Segundo Oliveira (1999), o mercado de trabalho pode ser definido como o local em que se encontram disponíveis as atividades em que contratantes encontram executores que cumpram tais trabalhos e, executores encontram contratantes interessados nos conteúdos deste trabalho-

Silva e Kassouf (2000) constatam que o mercado de trabalho é um dos temas que aparece em maior evidência, tanto na mídia, como na agenda política, especialmente em função das altas taxas de desemprego e da precariedade na inserção da população brasileira, em especial do jovem, nesse mercado. Eles detectam também, que as dificuldades presenciadas pelos jovens no Brasil no mercado de trabalho, tais como altas taxas de desemprego, baixa renda, falta de perspectivas profissionais, tornam o quadro social ainda mais precário devido à marcante interdependência existente entre estas variáveis e outras como baixa escolaridade, violência, além de outras.

Dados do IBGE (2008) mostram que, no Brasil, apenas 36\% dos jovens entre 15 e 24 anos têm emprego, outros $22 \%$ já trabalharam, mas estão desempregados atualmente. Em média, os jovens demoram 15 meses para conseguir o primeiro emprego ou uma nova ocupação nas regiões metropolitanas. No total, $66 \%$ deles precisam trabalhar porque todo seu ganho, ou parte dele, complementa a renda familiar. Curiosamente, o mercado de trabalho para os jovens apresenta um maior número de desempregados entre àqueles escolarizados. Na faixa de 15 a 17 anos, por exemplo, o nível de ocupação teve uma redução de nove pontos percentuais, caindo de $39 \%$ em 1996 para 30\% em 2006. No grupo de 18 e 19 anos, a queda foi de mais de três pontos, indo de $55,1 \%$ em 1996 para 51,8\% em 2006.

Camarano, Kanzo, Vianna e Pazinato (2003) acreditam que o período de inserção no mercado de trabalho é, provavelmente, um período instável e incerto e é um passo importante para a transição da juventude para a idade adulta. Pode representar, ao mesmo tempo, uma fonte de esperanças no futuro, pela possibilidade de mobilidade social e/ou de frustrações, pode significar também rotinas, precariedade e exclusão social.

\subsubsection{ESCOLHA PROFISSIONAL}

Delinear o perfil motivacional e a inclinação de carreira do estudante e do profissional de Secretariado permitirá compreender a influência dos valores humanos na determinação das inclinações profissionais, o que facilita conhecer como as predisposições profissionais recebem

Revista de Gestão e Secretariado - GeSec, São Paulo, v. 6, n. 1, p 48-73, jan./abr. 2015. 
influência da centralidade do sistema cognitivo, isto é, dos valores, concebidos como critérios capazes de influenciar as ações, escolhas e comportamento humano, interferindo na maneira pela qual o indivíduo julga a si mesmo e os outros. Nesse sentido, os valores humanos afetam as ações das pessoas sobre seu trabalho; aliados às motivações e ao talento, estimulam as decisões de carreira (Schein, 1993, citado por, Oliveira e Müller, 2010).

De acordo com Oliveira e Müller (2010), em pleno século XXI, o desenvolvimento de uma carreira profissional em uma única organização, objetivando o emprego seguro por toda uma vida, é um conceito em extinção. Atualmente, os profissionais buscam para si uma carreira que evite a obsolescência, que permita seu desenvolvimento até os mais altos níveis hierárquicos e que se tornem, cada vez mais, independentes da organização.

Schein (1990 citado por Côrtez \& Silva, 2006) sugere a adoção de uma noção ampliada de carreira, como um conjunto de atividades e experiências ocupacionais que constroem a vida profissional do indivíduo. Segundo o autor, as pessoas não buscam, porém, seu crescimento profissional de forma padronizada, sendo variados os tipos de "âncoras" por elas utilizadas, no esforço de construção de suas carreiras.

Nesse sentido, Schein (1990) identifica oito grupos de indivíduos:

1. Aqueles que buscam a estabilidade e segurança no trabalho, preferindo colocar em segundo plano o tipo de atividade desempenhada, priorizando a segurança financeira, benefícios e uma aposentadoria tranquila;

2. os que buscam maior independência e autonomia em sua atividade profissional e que, por isso, tendem a possuir alto grau de rejeição a regras, normas e rotinas;

3. os que possuem maiores competências técnicas e funcionais e buscam maximizá-las, aceitando atuar, por exemplo, como gerentes em suas áreas, mas evitando gerenciar todo o departamento;

4. os que buscam crescer na hierarquia da organização e, para isto, procuram desenvolver, por exemplo, uma visão mais geral sobre a empresa e fortalecer a sua rede interna de relacionamentos;

5. os que possuem um grau de criatividade elevado e que se sentem capazes de tangibilizá-lo, tendendo a visualizar a possibilidade de abertura de seus 
próprios negócios;

6. os que possuem habilidades para trabalhar em áreas específicas e buscam, prioritariamente, o desenvolvimento em suas atividades;

7. os que são movidos pela busca por superar barreiras e vencer desafios;

8. e os que priorizam a conciliação de sua vida profissional com a vida pessoal, ainda que isso possa penalizar o seu crescimento nas organizações.

\subsection{TEORIAS MOTIVACIONAIS}

Observa-se que, recentemente, a preocupação em relação ao fenômeno da motivação tem mudado de sentido. Passamos a entender que cada pessoa já traz dentro de si suas próprias motivações. Aquilo que mais interessa, então, é encontrar e adotar recursos organizacionais capazes de não sufocar as forças motivacionais inerentes às próprias pessoas. O importante é agir de tal forma que as pessoas não percam a sua sinergia motivacional (Maciel \& Sá, 2007).

Para entender o que é motivação, precisamos buscar suas causas, ou seja, os motivos que impelem as pessoas a agirem de certa maneira. A motivação relaciona-se intimamente com a personalidade do homem e com seu desenvolvimento mental, emocional, profissional e social. Ela incita as pessoas a se superar e a persistir na consecução dos objetivos que almejam. Canalizá-la em benefício da organização e das pessoas que a serve é de inquestionável relevância para o sucesso de qualquer empreendimento coletivo (Faller, 2004).

De modo geral, Chiavenato (1999) define motivação como tudo aquilo que impulsiona a pessoa a agir de determinada forma ou, pelo menos, que dá origem a uma propensão, a um comportamento específico. Esse impulso à ação pode ser provocado por um estímulo externo (provindo do ambiente) ou também ser gerado internamente nos processos mentais do indivíduo.Tadin, Rodrigues, Dalsoquio, Guabiraba e Miranda (2005) afirmam que as necessidades humanas, tidas como forças ativas e impulsionadoras do comportamento, são diversas. Isso porque as pessoas são diferentes entre si, possuem necessidades diferentes e estas, consequentemente, produzem padrões de comportamento que variam de indivíduo para indivíduo. Entretanto, segundo os mesmos autores, apesar de todas essas diferenças consideráveis entre os indivíduos, em pesquisas realizadas acerca do comportamento humano, foi constatado que o processo que dinamiza o comportamento humano é mais ou menos semelhante para todas as pessoas.

A motivação é objeto de estudo da Psicologia. Diversas correntes tentam explicar os processos motivacionais. Essas teorias são derivadas de quatro movimentos principais: behaviorista,

Revista de Gestão e Secretariado - GeSec, São Paulo, v. 6, n. 1, p 48-73, jan./abr. 2015. 
cognitivista, humanista e psicanalítico. As teorias podem ser influenciadas por mais de um desses movimentos (Penna, 2001).

Teorias mecanicistas enxergam o ser humano como um organismo passivo que é conduzido pelas influências e estímulos do ambiente em que está. Já a teoria organísmica enxerga o ser humano como um ser ativo. Nessa perspectiva, como organismo ativo, o ser humano tem necessidades intrínsecas psicologicamente inatas, sendo esta última concepção a base para a Teoria da autodeterminação (Deci \& Ryan, 1985, citado por, Maciel, 2008).

\subsubsection{TEORIA DA AUTODETERMINAÇÃO}

Maciel (2008) afirma que dentre as concepções teóricas de motivação, a Teoria da autodeterminação é recente, tendo sido divulgada por Deci, Ryan e seus colaboradores, na obra Intrinsic Motivation and self-determination in human behavior, publicada em 1975. As bases dessa teoria situam-se no estudo dos componentes de motivação intrínseca e de motivação extrínseca. Os motivos intrínsecos resultam da própria vontade do indivíduo; é uma forma de pensar e de agir que cada ser humano traz dentro de si. Os motivos extrínsecos dependem de fatores externos.

Para a Teoria da autodeterminação, o conceito de autonomia é atrelado ao desejo ou vontade do organismo (ativo) em organizar e desempenhar suas atitudes, experiências, comportamentos e assim, integrá-los ao sentido do self. Nesta concepção, as pessoas realizariam suas atividades por acreditarem que as fazem por vontade própria, pois acreditam na importância e atribuem significado no que fazem (Maciel, 2008).

O construto motivação pode ser entendido como determinantes ambientais, forças internas (necessidades e desejos) e incentivos que movem o organismo a executar uma determinada tarefa. A motivação vai além do comportamento e além dos fatos; compreende as propriedades e características do comportamento de forma analítica sem levar este termo a distorções de ordem, classificação e conceitos (Witter \& Lomônaco, 1984).

$\mathrm{Na}$ Teoria da autodeterminação, as motivações dos indivíduos diferem e são determinadas e orientadas por contextos que dão subsídios a necessidades psicológicas; postulam a autonomia, competência e conectividade dos seres que podem variar em relação ao nível e tipo de motivação. Nesse contexto, surge o motivo de alguém querer fazer algo por prazer e pela intensidade de realizar uma tarefa, no sentido de estar intrinsecamente motivado, e também por consequência, 
devido a outras variáveis envolvidas, na situação de estar extrinsecamente motivado (Sobral, 2003).

Segundo Guimarães e Boruchovitch (2004), a Teoria da autodeterminação busca entender os componentes da motivação intrínseca e da motivação extrínseca e os fatores que resultam com sua promoção. Nessa perspectiva, é essencial a satisfação das necessidades psicológicas. Essa teoria adota como necessidades básicas de realização a autonomia, a competência e o vínculo. É fundamental para a autorrealização que essas necessidades sejam satisfeitas.

As motivações intrínseca e extrínseca são de fundamental importância em todos os aspectos da vida, sendo presentes em todo o comportamento humano e resultam no desenvolvimento do aprendizado, sendo vistas de forma global. São oriundas das necessidades psicológicas de competência e de determinação. (Fernandes \& Raposo, 2005).

De acordo com a Teoria da autodeterminação, os fatores ambientais afetam a motivação intrínseca com os processos cognitivos, ou seja, os comportamentos serão influenciados pelo sistema social e contextual no qual estamos inseridos e vislumbra atender a três necessidades básicas: competência, autonomia e vínculo de relacionamento.

Para Maciel (2008), a Teoria da autodeterminação é uma macroteoria que tem estudado nos últimos 30 anos o desenvolvimento da personalidade saudável e da autorregulação autônoma, considerando e enfatizando as fontes motivacionais. Esta acredita que as tendências naturais para o crescimento e as necessidades psicológicas interagem com as condições sociais que nutrem ou frustram essas fontes motivacionais naturais, interferindo nas percepções pessoais de competência, autonomia e vínculo.

White (1975, citado por Guimarães, 2004) utilizou o termo competência para definir a capacidade do organismo de interagir satisfatoriamente com o meio em que está inserido. Para isto, faz-se necessário que os organismos aprendam e desenvolvam as capacidades exigidas por tal meio. Sendo assim, a experiência de dominar uma atividade desafiadora, aumentaria a competência do indivíduo, trazendo emoções positivas que de acordo com o autor seriam as "sensações de eficácia".

Outra necessidade psicológica básica, de acordo com Maciel (2008), além da autonomia e competência, é a necessidade de o organismo sentir que pertence ao meio em que está, ou seja, vinculado ao meio. Esta é vista como um "pano de fundo" das necessidades básicas que determinam a motivação intrínseca, pelo fato de organismos intrinsecamente motivados realizarem suas atividades de forma isolada, independentes de fatores externos. Porém, a necessidade de pertencer contribui com a sensação de segurança que possibilita o desenvolvimento inato das demais necessidades.

Revista de Gestão e Secretariado - GeSec, São Paulo, v. 6, n. 1, p 48-73, jan./abr. 2015. 


\subsection{ADMINISTRAÇÃO PÚBLICA BRASILEIRA}

Para Meirelles (2004), a Administração Pública significa a totalidade de serviços e entidades ligados ao Estado. De modo concreto, é esse mesmo Estado atuando solidamente visando satisfazer o bem comum de indivíduos em uma coletividade sob seu domínio, nas esferas federal, estadual e municipal de governo, podendo estas duas últimas esferas, gozarem de maior ou menor autonomia político-administrativa em relação à primeira.

Conforme conceituado por Bobbio, Matteucci \& Pasquino (1986, citado por Meirelles, 2004), de forma mais ampla, “[...] a expressão Administração Pública designa o conjunto das atividades diretamente destinadas à execução concreta das tarefas ou incumbências consideradas de interesse público ou comum, numa coletividade ou organização estatal”.

O Estado pode assumir as formas: Unitário ou Simples e Federativo. No modo Unitário, prevalece uma centralização tanto política quanto administrativa. Isto é possível por meio da instituição de três poderes - Executivo, Legislativo e Judiciário - independentes, porém únicos para toda a extensão territorial que compõe determinado Estado. Assim, é definida uma unidade de poder central da qual emanam todos os ordenamentos administrativos, judiciais e legais. Ainda que possa haver certa descentralização de poder, via entes regionais, estes últimos não possuem autonomia político-administrativa, subordinando-se ao poder central. (Junquilho, 2010)

Já no Estado federativo, os entes regionais - Estados e municípios -, por delegação de uma Constituição Nacional, detêm autonomias que lhes são próprias, não podendo suas competências administrativas, legislativas e políticas serem retiradas por um ato arbitrário e unilateral do poder central, como no Estado Unitário. (Brasil, 1998)

Desse modo, cada ente regional, pode, preservando diretrizes constitucionais únicas e nacionais, criar suas legislações, definir suas ordenações administrativas e instâncias jurídicas próprias. Não há aí um centro único de poder (federal), mas sim um compartilhamento desse mesmo poder de Estado entre entes descentralizados regionalmente (Estados e municípios, como no caso do Brasil de hoje). (Brasil, 1998)

Para tanto, o Estado é organizado por meio da Administração denominada de centralizada, ou direta, envolvendo entidades estatais como ministérios, secretarias; e indireta, constituída por entidades autárquicas, empresas públicas ou fundacionais, bem como por entidades de cooperação ou paraestatais, ou seja, aquelas pessoas jurídicas de direito privado, mas que atuam em cooperação 
com o Estado para a realização de interesses estatais. Há, ainda, as organizações não estatais, mas que prestam serviços de interesse público, porém não privativos de Estado, como as Organizações Não Governamentais (ONGs). (Junquilho, 2010)

\subsubsection{CONTEXTUALIZAÇÃO DA NOVA ADMINISTRAÇÃO PÚBLICA}

Até 1985, o Estado brasileiro era o ator principal que bancava parte do desenvolvimento econômico; porém, ele começou a dar sinais de incapacidade financeira para continuar mantendo esse papel.

\footnotetext{
Nas últimas décadas, os brasileiros estiveram engajados no processo de redemocratização do país, buscando reformar o Estado e construir um modelo de gestão pública capaz de torná-lo mais aberto às necessidades dos cidadãos brasileiros, mais voltado para o interesse público e mais eficiente na coordenação da economia e dos serviços públicos (Paula, 2005).
}

De acordo com Pereira (1997), o modelo burocrático adotado como modelo administrativo vigente para a administração indireta teve como consequência o incremento na ineficiência alocativa. A instituição de um rígido controle de processos em lugar do controle por resultados exacerbou a morosidade da administração. Dificuldades na contratação de pessoal, na execução das compras e no manejo dos recursos orçamentários também passaram a caracterizar a administração indireta. Todos esses elementos não foram acompanhados de uma melhoria qualitativa ou quantitativa na prestação dos serviços públicos, objetivo declarado dos constituintes, contribuindo, ao contrário, para dificultar ainda mais o atendimento das demandas da população.

Bresser-Pereira e Spink (2005) afirmam que, foi com a redemocratização do Brasil, que se iniciou uma reforma estatal, que tinha como pilares, a ideia de redução da presença do Estado, tanto no plano econômico, como indutor e executor de políticas de desenvolvimento, como no plano das políticas de cunho social.

Com as novas inspirações ideológicas, começou-se a delinear a ideia de que os governos não poderiam sozinhos conduzir ao progresso. O desenvolvimento passou a ser visto como algo complexo e gigantesco, e as máquinas administrativas tradicionais não como fator de modernização, mas obstáculos ao progresso. Surgiram movimentos significativos, em muitos países e apoiados por entidades internacionais, para proclamar a descrença nas possibilidades da administração pública de conduzir o desenvolvimento (Motta, 2007).

$\mathrm{Na}$ perspectiva da reforma gerencial, o papel do Estado, contrapondo-se ao modelo do Estado Social Burocrático, seria o do Estado Social Liberal. Deste modo, no governo FHC, que teve inicio com a posse da presidência por Fernando Henrique Cardoso no ano de 1995 e findou-se no 
ano de 2003, a Administração Pública Gerencial foi um instrumento por meio do qual se buscava prevalecer, então, valores vinculados à qualidade, à eficiência e à eficácia dos serviços públicos, e à busca pelo estabelecimento de uma cultura gerencial em distinção à cultura burocrática nas organizações públicas. Ainda assim, não se tratava de negar totalmente os princípios do modelo burocrático, preservando deles o interesse público, os sistemas de méritos e de carreiras estruturadas de funcionalismo, a avaliação de desempenho e a formação continuada de pessoal (Bresser-Pereira e Spink, 2005).

Como afirma Motta (2007), reduzir o tamanho do Estado e modernizar a administração pública tornaram-se pontos importantes de uma nova agenda política. Ao contrário das experiências anteriores, essa modernização se inspirou fortemente nos modelos de gestão privada, considerados superiores e mais eficazes. Assim, as principais mudanças seriam transferir funções estatais para a área privada e as restantes seriam administradas com formas o mais próximo possível das praticadas nas empresas privadas.

Nesse sentido, Guimarães (2002) acrescenta que as tentativas de inovação na administração pública significam a busca de eficiência e da qualidade na prestação dos serviços públicos. E para que isso ocorra, são necessários o rompimento com os modelos tradicionais de administrar os recursos públicos e a introdução de uma nova cultura de gestão.

\subsubsection{INGRESSO NO SERVIÇO PÚBLICO}

O sistema jurídico brasileiro garante a igualdade de acesso a todos os interessados em ingressar na carreira pública. De acordo com emenda constitucional no 19, de 4/6/1998 Inciso II, do art. 37:

\footnotetext{
II - a investidura em cargo ou emprego público depende de aprovação prévia em concurso público de provas ou de provas e títulos, de acordo com a natureza e a complexidade do cargo ou emprego, na forma prevista em lei, ressalvadas as nomeações para cargo em comissão declarado em lei de livre nomeação e exoneração. (Brasil, 2011)
}

Conforme explicitado por Dallari (2006), todo brasileiro tem constitucionalmente assegurado o direito, de, por qualquer forma, participar da administração pública, direta ou indiretamente, mesmo quando ela se apresenta com uma roupagem de pessoa jurídica de direito privado. 
A licitação e o concurso público foram destacados por Bacellar Filho (2011) como os dois principais instrumentos de garantia da profissionalização da atividade administrativa do Brasil. Ambos os certames destinam-se à seleção de agentes qualificados, do ponto de vista técnico, para o desempenho de atividades inerentes a Administração Pública. O concurso público é um mecanismo de seleção para servidores públicos, de pessoas físicas que prestam serviço ao Estado com vínculo empregatício e mediante remuneração paga pelos cofres públicos.

Segundo Bresser-Pereira e Spink (2005), foi a Constituição de 1988 que tornou obrigatório o concurso público para a admissão de todo e qualquer funcionário, e ele afirma ter sido esse o grande mérito da Constituição, pois representou grande avanço, na medida em que dificultou o empreguismo, termo que segundo Novo Dicionário Aurélio é a tendência a dar empregos públicos à farta, por conveniências políticas. (Ferreira, 1998)

Nesse sentido, a Lei 8.112, de 11 de dezembro de 1990, veio para regulamentar todo o regime jurídico dos agentes e servidores públicos federais, ou seja, os servidores públicos que prestam seus serviços para União, autarquias e fundações federais e que são regidos pelo regime estatutário.

Conforme definido no segundo e terceiro artigo desta lei, o conceito de Servidor e Cargo público, respectivamente: Servidor é a pessoa legalmente investida em cargo público; Cargo público é o conjunto de atribuições e responsabilidades previstas na estrutura organizacional que devem ser cometidas a um servidor. (Brasil, 1990)

Segundo Santos (2006), o cargo público é o menor centro hierarquizado de competência da administração direta, autárquico e fundacional público, criado por lei, com denominação própria e quantidade definida. Os servidores públicos civis são estatutários que seguem um regime jurídico de natureza pública e trabalham na administração direta, nas autarquias e nas fundações públicas.

Como ressaltado por Santos (2006), após três anos de efetivo exercício, o servidor adquire a condição de estabilidade no serviço público (art. 21 do Regime Jurídico), sendo essa uma característica distintiva do servidor público. A partir daí, o servidor apenas perderá o cargo "em virtude de sentença judicial transitada em julgado, de processo administrativo ou insuficiência de desempenho, no qual lhe sejam assegurados o contraditório e a ampla defesa” (art. 22).

Com o objetivo de reestruturar o desenvolvimento da carreira dos servidores técnicoadministrativos aos objetivos institucionais, os servidores ingressantes por meio de concurso público no âmbito das IFES vinculadas ao Ministério da Educação estão regidos pelo Plano de Carreira dos Cargos Técnico-administrativos em Educação (PCCTAE).

Revista de Gestão e Secretariado - GeSec, São Paulo, v. 6, n. 1, p 48-73, jan./abr. 2015. 
O PCCTAE regulamentado pela Lei 11.091, de 12/1/2005, dá diretrizes aos servidores públicos quanto à sua carreira e é estruturado em cinco níveis de classificação, categorizados como A, B , C, D e E, sendo que o nível E abrange cargos de nível superior. Os cargos são classificados "a partir do requisito de escolaridade, nível de responsabilidade, conhecimentos, habilidades específicas, formação especializada, experiência, risco e esforço físico para o desempenho de suas atribuições" (Brasil, 2005).

\subsection{O SECRETARIADO EXECUTIVO E O CURSO DA UFV}

O curso de Secretariado Executivo Trilíngue da UFV foi idealizado, criado e implantado pelo Professor Maurício Xavier. Iniciou-se em 1991 como uma habilitação do curso de Letras Secretário Executivo Português-Inglês ou Português-Francês. Em 1997, foi aprovada a transformação da habilitação para o curso de Secretariado Executivo Trilíngue - Português, Francês, Inglês. Desde seu reconhecimento pelo Ministério da Educação (MEC) em 2003, várias mudanças têm ocorrido no intuito de alcançar uma melhora contínua na formação do profissional e de adaptação às diretrizes curriculares estabelecidas pelo MEC.

Antes com apenas vinte vagas anuais, desde o vestibular de 2009, o curso passou a oferecer mais cinco vagas, pois as instituições que aderiram ao programa Reuni, Programa de Apoio a Planos de Reestruturação e Expansão das Universidades Federais, receberam financiamentos para o aumento do número de vagas e de cursos. Esse incremento expressivo na quantidade de vagas ofertadas demonstra o aumento pela procura de formação profissional na área, bem como sugerem a consolidação do curso e da profissão. (UFV, n.d.)

Rauber e Rauber (2013) destacam a diversidade e a importância das grades curriculares dos Cursos de Graduação em Secretariado Executivo, pois englobam disciplinas de Línguas, Comunicação, Metodologia de Pesquisa, Administração, Sociologia, Psicologia, Contabilidade, Economia, Direito, Ética e Informática, além das Técnicas de Secretariado, Gestão Estratégica e Secretarial e Estágio Supervisionado. Os autores afirmam que "toda essa carga de conhecimento visa a dar ao futuro Secretário Executivo uma visão sistêmica da realidade organizacional onde ele vai desempenhar suas funções, sabendo que a própria organização faz parte de algo maior”.

Nesse sentido, além de ser enquadrado na modalidade trilíngue, o curso da UFV implementou uma mudança de catálogo em 2008, visando aprimorar a formação dos discentes 
frente às demandas organizacionais do mercado de trabalho. Para tanto, passaram a ser oferecidas as disciplinas de Espanhol e de Gestão Secretarial e Empreendedora; e disciplinas antes optativas como Introdução à Economia, Metodologia de Pesquisa Aplicada ao Secretariado, Organização, Sistemas e Métodos, e, Assessoria Executiva e Gestão Estratégica passaram a ser obrigatórias (UFV, n.d.).

Além das diversificadas disciplinas, para melhor consolidação da sua formação e consequente inserção no mercado de trabalho, o curso de Secretariado Executivo Trilíngue da UFV possibilita que os alunos exerçam várias atividades, como estágios extracurriculares; participação em organizações de eventos; monitorias de línguas estrangeiras; projetos de pesquisa e de extensão; intercâmbios e atuação na Empresa Júnior do curso, a SEC Jr. Consultoria.

Sabino e Rocha (2004) afirmam que o Secretário é definido como "um profissional administrativo que possui um domínio de habilidades de escritório, demonstra a habilidade para assumir responsabilidade sem supervisão direta, iniciativa de exercícios e julgamento, e toma decisões dentro do âmbito de autoridade".

Para garantir os saberes necessários ao desenvolvimento da competência, institui-se, a partir das Diretrizes Curriculares Nacionais (DCN) do MEC, em parágrafo único do artigo $3^{\circ}$, que:

\footnotetext{
o bacharel em Secretariado Executivo deve apresentar sólida formação geral e humanística, com capacidade de análise, interpretação e articulação de conceitos e realidades inerentes à administração pública e privada, ser apto para o domínio em outros ramos do saber, desenvolvendo postura reflexiva e crítica que fomente a capacidade de gerir e administrar processos e pessoas, com observância dos níveis graduais de tomada de decisão, bem como capaz para atuar nos níveis de comportamento microorganizacional, mesoorganizacional e macroorganizacional (2005).
}

Além das competências técnicas e requisitos necessários para o exercício do cargo, Rauber e Rauber (2013) destacam as principais habilidades e competências a serem exibidas pelos profissionais da área, a seguir:

1. Capacidade de articulação e operacionalização com o público interno e externo;

2. habilidade de utilização de raciocínio lógico, crítico e analítico para interpretar e encaminhar situações organizacionais;

3. capacidade de organização e sistematização de procedimentos de trabalho para assessoria das equipes que secretaria;

4. aptidão para estabelecer processos de comunicação verbal e não verbal entre público interno e externo, viabilizando os inter-relacionamentos;

Revista de Gestão e Secretariado - GeSec, São Paulo, v. 6, n. 1, p 48-73, jan./abr. 2015. 
5. capacidade de organização e administração dos fluxos informacionais e destreza na intermediação das relações interpessoais focado na gestão de resultados;

6. habilidade de lidar com modelos inovadores de gestão;

7. receptividade e liderança para o trabalho em equipe, na busca da sinergia; e

8. maestria no fornecimento de apoio logístico, disponibilizando informações e alternativas para os decisores.

\section{PROCEDIMENTOS METODOLÓGICOS}

O presente estudo é baseado em uma pesquisa exploratória, de caráter qualitativo, que se restringiu apenas a um segmento da Administração Pública que são as IFES e que pode servir de base para futuros estudos em outras instituições públicas ou mesmo nas IFES em questão, com uma amostra ampliada. Essa delimitação justifica-se pelo aumento, nos últimos anos, do número de vagas abertas nos concursos das IFES para o cargo de Secretariado Executivo.

De acordo com Gil (1987), pesquisa é "um procedimento racional e sistemático que tem como objetivo, proporcionar respostas aos problemas que são propostos”. Frequentemente, a pesquisa se origina a partir de uma dúvida ou problema. A partir disso, buscam-se soluções por meio da utilização do método científico. A questão fundamental a ser respondida por esta pesquisa foi: quais fatores influenciam os egressos do curso de Secretariado Executivo Trilíngue da UFV a ingressarem no serviço público?

Este trabalho baseou-se na pesquisa bibliográfica, realizando-se o levantamento bibliográfico necessário à fundamentação teórica do estudo, como é habitual em investigações científicas.

A amostra da pesquisa é constituída pelos egressos do Curso de Secretariado Executivo da UFV que foram aprovados em concurso público nas IFES de Minas Gerais e na UNB (Distrito Federal). A amostra é composta por 20 pessoas, entretanto, houve um retorno de 13 questionários, o que corresponde a $60 \%$ da amostragem total. A escolha dessas instituições se justifica pelo fato de termos uma amostra representativa de alunos aprovados. Sendo elas: Universidade Federal de 
Minas Gerais - UFMG, Universidade Federal de Itajubá - Unifei, Universidade Federal de Ouro Preto - UFOP, Universidade Federal Viçosa - UFV, Universidade Federal de São João Del-Rei UFSJ, Universidade Federal do Vale do Jequitinhonha e Mucuri - UFVJM, Universidade Federal de Alfenas - Unifal, Universidade Federal de Juiz de Fora - UFJF, Universidade de Brasília UNB.

Constatou-se que as IFES vêm notadamente buscando cada vez mais qualificação do seu corpo técnico administrativo através de concursos públicos. Desse modo, fez-se um levantamento das principais instituições que tinham em seu quadro de funcionários, egressos do curso de Secretariado Executivo da UFV, aprovados para o cargo de Secretário ou Secretária Executiva.

Nesse sentido, a partir de um levantamento apurado, tendo como base os últimos concursos públicos das IFES, observou-se ainda que algumas dessas instituições não abriram vaga para o cargo de Secretariado Executivo, ou se o fizeram, não tiveram aprovados advindos da instituição em questão. Sendo assim, tais instituições não foram citadas na pesquisa.

Para descrever o perfil motivacional dos acadêmicos de Secretariado Executivo, o questionário utilizado foi semiestruturado e de múltiplas escolhas.

$\mathrm{Na}$ primeira parte do questionário, por meio de 10 perguntas, pretendeu-se identificar o perfil da amostra. As perguntas abrangeram os seguintes temas: sexo, idade, estado civil, ano de ingresso e ano de conclusão do curso, razão da escolha do curso, adequação ao perfil exigido e plano pessoal de carreira.

Dando continuidade às questões, a parte 2 do questionário, composta por 12 perguntas, teve por objetivo prospectar informações acerca do curso na visão dos egressos quanto à grade curricular e a motivação para o ingresso no curso.

No último bloco, contendo as oito perguntas finais do questionário, pretendeu-se identificar quais são as opiniões do egresso do curso de Secretariado Executivo da UFV quanto ao mercado de trabalho atual, como o profissional está inserido nesse contexto e o que os motivou a optar pelo setor público.

Os dados coletados por meio dos questionários foram informatizados em arquivo eletrônico e a análise dos dados foi feita através do software online esurveypro, ferramenta online gratuita utilizada em pesquisas que auxilia na elaboração de questionários.

A ferramenta utilizada foi a distribuição estatística descritiva simples que possibilitou identificar as opções com maior incidência de resposta, bem como estabelecer tendências e relações entre respostas.

Revista de Gestão e Secretariado - GeSec, São Paulo, v. 6, n. 1, p 48-73, jan./abr. 2015. 


\section{ANÁLISE E DISCUSSÃO DOS RESULTADOS}

A seguir são apresentadas todas as informações coletadas na pesquisa, relativas ao perfil profissional de Secretariado Executivo da UFV. Durante o preenchimento do questionário, o egresso pôde, em determinadas questões, optar por mais de uma alternativa. Sendo assim, justificase o motivo de algumas respostas apresentarem um total superior a $100 \%$.

Em relação ao perfil do egresso, $15 \%$ são do sexo masculino, sendo $85 \%$ do sexo feminino; $30 \%$ dos respondentes estão entre 25 e 30 anos, $53 \%$ estão entre 20 e 25 anos, estando os $15 \%$ restantes entre $35-40$.

Questionou-se aos egressos, o que os motivou a escolher o curso. O resultado mostra que: $29,17 \%$ dos entrevistados escolheram o curso por acreditar que ele ofereceria boas perspectivas de atuação no mercado de trabalho, já o percentual de alunos que escolheu o curso por afinidade foi de $25 \%$. Percebeu-se também que o fator qualidade da Universidade foi determinante para 16,67\% dos entrevistados. A influência de parentes e amigos foi apontada como fator de escolha para 8,33\%. Com 4,17\% estão os fatores, curso superior gratuito e atuação prévia na área. Os demais (12,5\%) não se encaixaram em nenhuma das respostas, tendo como fator motivador na escolha do curso outros motivos.

Como define Chiavenato (1999), motivação é tudo aquilo que impulsiona a pessoa a agir de determinada forma, podendo esse impulso ser provocado por um estímulo externo ou pode também ser gerado internamente nos processos mentais do indivíduo. No caso dos entrevistados, os estímulos externos seriam a influência dos pais e amigos ou boas perspectivas de atuação no mercado de trabalho, já os estímulos internos encontrados nessa questão podem ser a escolha por afinidade com o curso ou mesmo pelo fato de o curso ser gratuito.

Quando questionados sobre o perfil pessoal e profissional, constatou-se que 76,92\% dos entrevistados acreditam ter perfil compatível com o do curso, o restante $(23,08 \%)$ não tem certeza. Quanto ao plano de carreira dos entrevistados, detectou-se certa incerteza, pois $61,54 \%$ tinham em mente o que estariam fazendo em 10-15 anos quando ingressaram na universidade, porém, ao somarmos o percentual dos que mudaram de ideia durante a graduação, temos 53,85\%.

No último item desse bloco de questões, houve uma preocupação em identificar se o entrevistado acredita que carreira e realização pessoal estão diretamente relacionadas. A partir das respostas, temos uma maioria de $76,92 \%$ afirmando que a carreira contribui para a realização

Revista de Gestão e Secretariado - GeSec, São Paulo, v. 6, n. 1, p 48-73, jan./abr. 2015. 
pessoal. Em contrapartida, 7,69\% acreditam que sonho e carreira são coisas diferentes e $15,38 \%$ responderam que nunca pensaram no assunto.

No segundo bloco de questionamentos, objetivou-se a prospecção de informações acerca do curso na visão dos egressos quanto à grade curricular e à motivação para o ingresso no curso.

Ao serem questionados sobre como conheceram o curso de Secretariado Executivo, 38,46\% dos entrevistados disseram que o conhecimento do curso se deu através de amigos e parentes que sabiam algo sobre o curso, 30,77\% por meio da escola que estudavam, 23,08\% por meio de um profissional/ estudante/ professor desta área e 7,69\% por revistas, jornais, TV, ou outros meios de comunicação.

Quanto às expectativas em relação ao curso antes de entrar na universidade, notou-se que um grande percentual $(53,85 \%)$ dos entrevistados acredita que o curso é direcionado ao mercado de trabalho. Outros 30,77\% veem o curso como correspondente ao seu perfil ou aptidão, e 15,38\% apontam o curso como inovador.

Sobre as motivações do egresso no decorrer do curso, o questionário revelou que 46,15\% foram motivados pelos trabalhos e estágios que realizaram na área. Para 23,08\%, a motivação que tiveram está relacionada aos professores e à universidade que colaboraram para a realização de algumas atividades, como estágio e iniciação cientifica. Com percentual semelhante (23,08\%), algumas disciplinas ou uma área específica do curso foram apontadas também como motivadoras, e 7,69\% sentiram-se motivados por anúncios e propostas de um mercado promissor para o profissional.

As respostas obtidas a partir desses questionamentos corroboram o que Sobral (2003) afirma sobre a Teoria da autodeterminação. Para ele, as motivações dos indivíduos diferem e são determinadas e orientadas por contextos que dão subsídios a necessidades psicológicas; postulam a autonomia, competência e conectividade dos seres que podem variar em relação ao nível e tipo de motivação. Nesse contexto surge o porquê de querer fazer algo por prazer e a intensidade de realizar uma tarefa no sentido de estar intrinsecamente motivado e também por consequência ou devido a outras variáveis envolvidas, na situação de estar extrínseco motivado.

Essa heterogeneidade nas respostas dos entrevistados demonstra um dos aspectos da Teoria da autodeterminação, que é a autonomia. Os alunos, no decorrer do curso, desenvolvem as mais diversas atividades tais como: estágios, monitorias, projetos, dentre outros. Essas atividades, muitas das vezes, são desenvolvidas por interesse próprio do aluno, outras vezes não, e o fato de estar satisfeito, ou não, será determinante para o desenvolvimento da motivação.

Revista de Gestão e Secretariado - GeSec, São Paulo, v. 6, n. 1, p 48-73, jan./abr. 2015. 
No último bloco de perguntas do questionário foram obtidas informações acerca das percepções dos egressos do curso de Secretariado Executivo da UFV sobre mercado de trabalho e ingresso no setor público.

A primeira pergunta dessa parte do questionário foi: "Você acredita que o curso de Secretariado Executivo da UFV torna os profissionais aptos para as exigências do mercado de trabalho atual?". Pelos dados obtidos, verificou-se a satisfação dos egressos em relação ao curso da UFV, uma vez que 76,92\% responderam sim a esse questionamento.

No que diz respeito ao mercado de trabalho no setor privado, 84,62\% dos entrevistados estão positivos, enquanto $15,38 \%$ responderam que não há boas oportunidades.

$\mathrm{Na}$ questão seguinte, foi perguntado aos respondentes se o serviço público foi a primeira opção quanto a área de atuação do profissional de secretariado. Com as respostas obtidas, detectouse que o setor público não era a primeira opção de 69,23\% dos entrevistados. Com esse resultado concluímos que apesar de os entrevistados acreditarem que o setor privado oferece boas oportunidades, a maioria optou pelo setor público. Essa escolha pelo setor público pelos egressos de Secretariado Executivo é o que a Teoria da autodeterminação definiria como os comportamentos sendo influenciados pelo sistema social e contextual no qual se está inserido, ou seja, os fatores ambientais, como altas taxas de desemprego, grande rotatividade no setor privado, instabilidade, crises econômicas estariam afetando a motivação intrínseca. (Bergamini, 1997)

Em seguida, questionou-se sobre os vários fatores motivacionais que influenciaram na decisão de prestar concurso público. Pelas opções assinaladas pelos entrevistados, chegou-se à conclusão que segurança e estabilidade são os fatores principais na escolha pela carreira pública $(25,49 \%)$, uma vez que todos os entrevistados marcaram essa opção. Os fatores segurança e estabilidade também foram verificados na pesquisa de Côrtez e Silva (2006), como de destaque entre os fatores motivadores dos indivíduos que escolheram trabalhar em uma empresa estatal. Esses mesmos aspectos também foram apontados por cerca de $50 \%$ dos profissionais entrevistados no estudo Barreto, Nunes, Veiga, e Vilas Boas (2007).

Salários e benefícios aparecem em segundo lugar com 19,61\% no rol das motivações, em seguida temos qualidade de vida e influência de amigos com o mesmo percentual $(13,73 \%)$. Na sequência, aparecem os fatores possibilidade de crescimento/carreira e a não exigência de experiência prévia ou de critérios estereotipados como aparência com 7,84\% e com 1,96\% estão os fatores dificuldade de realocação no mercado de trabalho e menor discriminação quanto à idade,

Revista de Gestão e Secretariado - GeSec, São Paulo, v. 6, n. 1, p 48-73, jan./abr. 2015. 
sexo e universidade de formação.

Analisando esse resultado a partir do que afirmam Tadin et al. (2005) a respeito do comportamento humano, concluímos que os estudantes do curso de Secretariado Executivo da UFV, apesar de possuírem perfis distintos e produzirem padrões de comportamento individuais, eles dinamizam um comportamento humano semelhante. A grande maioria apontou Segurança/Estabilidade e salários e benefícios como os principais fatores motivacionais. .

Essa escolha pelo setor público pode ser justificada pelo sistema social e contextual nos quais os entrevistados estão inseridos. Atualmente, os jovens, prestes a ingressar no mercado de trabalho, procuram por estabilidade e segurança em primeiro lugar.

Quando questionados sobre os pontos positivos do setor público, segurança apareceu como ponto principal com $29,27 \%$, em segundo lugar está a chance de construir uma carreira e qualidade de vida com 17,07\%, em seguida estão oportunidade de treinamento/desenvolvimento e bons salários e benefícios com 12,20\%, possibilidade de gerenciamento de tempo aparece com 7,32\% e ambiente de trabalho favorável 4,88\%.

$\mathrm{O}$ aspecto segurança foi evidenciado pelas respostas dos entrevistados como o principal ponto positivo do setor público. Esse aspecto está definido em forma de lei, de acordo com os arts. 21 e 22 do Regime Jurídico que determinam que após três anos de efetivo exercício, o servidor adquire a condição de estabilidade no serviço público. A partir daí, o servidor apenas perderá o cargo "em virtude de sentença judicial transitada em julgado, de processo administrativo ou insuficiência de desempenho, no qual lhe sejam assegurados o contraditório e a ampla defesa".

Ao comparar as respostas obtidas sobre o serviço público, temos segurança e estabilidade como fatores primordiais influenciando a tomada de decisão dos egressos.

Questionados sobre as expectativas de permanecer na instituição em que estão, notou-se que o 53,85\% cogitam a possibilidade de sair para trabalhar em outra instituição, o restante dos entrevistados pensam em permanecer na organização e ficar até aposentar. Fica evidente a partir desse questionamento, que mesmo apesar de o serviço público não ter sido a primeira opção dos entrevistados ao ingressar no curso, atualmente, eles não pensam em trocá-lo pelo setor privado.

O último questionamento diz respeito ao principal fator que os levaria a deixar a instituição. A maioria $(37,50 \%)$ dos entrevistados respondeu que o principal fator seria passar em outro concurso público, os demais fatores tais como: receber uma oferta de melhor salário no setor privado; receber uma proposta desafiadora; oportunidades pessoais (estudar fora do país, fazer mestrado/doutorado); não encontrar possibilidade de crescimento; dentre outros; obtiveram 12,50\% das respostas. Mais uma vez, constatou-se por meio desses questionamentos, que os estudantes do

Revista de Gestão e Secretariado - GeSec, São Paulo, v. 6, n. 1, p 48-73, jan./abr. 2015. 
curso de SET prezam por segurança e estabilidade, pois somente uma minoria trocaria o setor público pelo privado.

\section{CONSIDERAÇÕES FINAIS}

O presente estudo explorou a experiência de transição universidade-mercado de trabalho entre jovens universitários do curso de Secretariado Executivo da UFV que optaram por seguir carreira no setor público. Dentro disso, especificamente objetivou-se: a) analisar os fatores motivacionais que influenciam os egressos do Curso de Secretariado Executivo na escolha pela carreira no setor público; b) definir o perfil dos estudantes de Secretariado Executivo, egressos da Universidade Federal de Viçosa no estado de Minas Gerais e Distrito Federal que foram aprovados em concurso público; c) verificar se os pressupostos das teorias motivacionais são aplicáveis à realidade dos estudantes do curso de Secretariado Executivo.

Ao analisar os dados coletados neste estudo notou-se que o fator motivacional estabilidade/segurança foi apontado como o mais determinante na escolha da carreira no funcionalismo público. Esse resultado pode indicar uma possível preocupação dos egressos do curso de Secretariado Executivo com a obtenção de uma fonte de renda estável e permanente frente às incertezas e mudanças no mercado de trabalho atual. Observou-se, também, que os participantes da pesquisa revelam uma percepção positiva do setor público, no que se refere à existência de oportunidades de crescimento profissional, aliada à possibilidade de um melhor gerenciamento da qualidade de vida.

Deve-se considerar, por fim, a limitação deste estudo pelo fato de os formandos que participaram do estudo serem de apenas um curso. Se por um lado essa característica do estudo homogeneizou o espectro de experiências específicas ao curso ressaltando as diferenças individuais, por outro, não permite uma transposição indiscriminada das conclusões para outros contextos.

Dessa forma, deve-se considerar que os informantes foram todos voluntários e oriundos de uma única instituição de ensino superior, cujo prestígio e qualidade de ensino, comprovados pelo conceito 5, nos anos 2007, 2009, 2012 no Enade, sendo escolhido como o melhor curso de Secretariado Executivo do país, é um fator que certamente influencia a colocação profissional de seus egressos. 
Assim, recomenda-se a realização de novos estudos sobre os fatores motivacionais de indivíduos que ingressaram em organização do setor público, por meio de questionários, em áreas de atuação diferentes, pois o estudo em questão focou nas IFES. Devido à diversidade de realidades encontradas nesse ambiente e das diferentes esferas existentes (federal, estadual e municipal), a questão requer uma análise mais abrangente que permita uma generalização dos resultados.

\section{REFERÊNCIAS}

Albornoz, S. (1994). O que é trabalho? São Paulo: Ed. Brasiliense.

Bacellar Filho, R. F. (2001). Profissionalização da função pública: A experiência brasileira. Cadernos da Escola de Direito e Relações Internacionais 01.

Barreto, D. F. da C; Nunes G. S; Veiga, J. L. B. C. \& Vilas Boas, A. A. (2007). Que fatores motivacionais que afetam os indivíduos que ingressam no setor público? O caso de uma empresa de energia. Gepros. Gestão da produção, operações e sistemas. (Ano 2, vol. 5, out-dez/2007 p. 11-24).

Bastos, A. V. B; Pinho, A. P. M, \& Costa, C. A. (1995). "Significado do trabalho: um estudo entre trabalhadores inseridos em organizações formais". Revista de Administração de Empresas": 2029.

Bergamini, C. W. (1997). Motivação nas organizações (4a ed.). São Paulo: Atlas.

Brasil. Constituição (1988). Constituição da República Federativa do Brasil. Brasília, Senado, 1998. Recuperado de http://www.planalto.gov.br

Brasil. Emenda Constitucional $\mathrm{n}^{\mathbf{0}}$ 19, promulgada em 4 de junho de 1998. Recuperado de http://www.planalto.gov.br

Brasil, L. F. Lei n. 8.112, de 11 de dezembro de 1990. Dispõe sobre o regime jurídico dos servidores públicos civis da União, das autarquias e das fundações públicas federais. Recuperado de http://www.planalto.gov.br

Brasil. Lei no 11.091, de 12 de janeiro de 2005. Dispõe sobre a estruturação do Plano de Carreira dos Cargos Técnico-administrativos em Educação, no âmbito das Instituições Federais de Ensino vinculadas ao Ministério da Educação, e dá outras providências. Diário Oficial da República Federativa do Brasil, Brasília, 13 jan. 2005. Recuperado de www.planalto.gov.br/legisla.htm.

Brasil. Ministério da Educação. Conselho Nacional de Educação. Câmara de Educação Superior. Resolução $\mathrm{n}^{\mathrm{o}} 3$, de 23 de junho de 2005. Recuperado de http://portal.mec.gov.br/cne/arquivos/pdf/rces003 05.pdf. 
Borges, L. O. \& Tamayo, Á. (2001). A estrutura cognitiva do significado do trabalho.Revista Psicologia, 1.2: 11-44.

Bresser-Pereira, L. C.; \& Spink, P. K. (2005). Reforma do Estado e administração pública gerencial. Rio de Janeiro: Editora FGV.

Camarano, A. A.; Kanzo, S.; Vianna, C. \& Pazinato, M. T. (2003). A transição para a vida adulta: Novos ou velhos desafios? Mercado de trabalho. Conjuntura e análise, n. 21, Brasília, Ipea, pp. 53-66.

Chiavenato, I. (1999). Gestão de pessoas: O novo papel dos recursos humanos nas organizações. Rio de Janeiro, RJ: Campus.

Côrtez, L. L.; \& Silva, J. R. G. (2006). Construção do contrato psicológico de indivíduos que ingressam em organizações do setor público no atual contexto brasileiro: Estudo de caso em uma empresa estatal. In Encontro anual da Associacão Nacional de Programas de pós-gradução em Administração, 2006, Salvador, Anais...

Dallari, A. A. (2006). Princípio da isonomia e concursos públicos. Revista Eletrônica de Direito de Estado. n. 6, abril/maio/junho de 2006, Salvador/Bahia. Recuperado de $\underline{\text { www.direitodoestado.com.br }}$

Faller, B. C. (2004). Motivação no setor público: Um estudo de caso da Secretaria de Administração da Prefeitura Municipal de Santa Cruz do Sul. Dissertação de Mestrado da Universidade Federal do Rio Grande do Sul, Programa de Pós- graduação em Administração. Porto Alegre, RS.

Fernandes, H, M. \& Raposo, J. V. (2005). Continuum de autodeterminação: Validade para a sua aplicação no contexto desportivo. Natal, Estud. psicologia.vol. 10 n.3, set./dez. 2005.

Ferreira, A. B. de H. (1988). Dicionário Aurélio Básico da Língua Portuguesa. Rio de Janeiro: Nova Fronteira.

Gil, A. C. (1987). Como elaborar projetos de pesquisa. São Paulo: Atlas.

Guimarães, S. $\quad$ E. $\quad$ R. (2004). Motivação intrínseca, extrínseca e o uso de recompensas em sala de aula. In E. Boruchovitch \& J.A. Bzuneck (orgs.) A motivação do aluno. Contribuições da psicologia contemporânea (pp.37-57). Petrópolis, RJ: Vozes.

Guimarães, S. E. R \& Boruchovitch, E. (2004). O estilo motivacional do professor e a motivação intrínseca dos estudantes: uma perspectiva da Teoria da Autodeterminação. Psicologia, Reflexão e Crítica. vol.17, $\mathrm{n}^{\circ} .2$, Porto Alegre. Recuperado de http:www.scielo.br

Guimarães, T. D. A. (2002). A nova administração pública e a abordagem da competência. Revista de administração pública, 34(3), 125-a. 
Junquilho, G. S. (2010). Teorias da administração pública. Florianópolis, Departamento de Ciências da Administração / UFSC; Brasília: Capes: UAB.

Maciel, A. G. (2008). As contribuições da Teoria da Autodeterminação para a Psicopedagogia. Especialização em Psicopedagogia. Instituto de Estudos Avançados e Pós-graduação, ESAP.

Maciel, S. E. V. \& Sá, M. A. D. de (2007). Motivação no trabalho: Uma aplicação do Modelo dos dois fatores de Herzberg. Studia Diversa, CCAE-UFPB, vol. 1, n. 1, p. 62-86, outubro 2007.

IBGE (2008). Mapa do mercado de trabalho. Recuperado de http://www.ibge.gov.br/home/estatistica/populacao.

Meirelles, H. L. (2004). Direito administrativo brasileiro (29a ed.). São Paulo: Malheiros.

Motta, P. R. (2007). A modernização da administração pública brasileira nos últimos 40 anos. $R A P$. Rio de Janeiro. (Edição Especial Comemorativa, pp. 87-96)

Oliveira, F. B. de \& Müller, E. S. M. (2010). O perfil motivacional e inclinação de carreira do estudante e do profissional da Tecnologia da Informação. Revista ADM.MADE, ano 10, vol.14, n.1, pp.51-73, janeiro/abril, 2010.

Oliveira, M. A. (1999). E Agora José? Guia para quem quer buscar emprego, mudar de trabalho, montar um negócio ou repensar sua carreira. São Paulo: Senac.

Paula, A. P. P de (2005). Administração pública brasileira entre o gerencialismo e a gestão social. RAE-Debate, vol. 45, n.1. ,36-49, 2005.

Penna, A. G. (2001). Introdução à motivação e emoção. Rio de Janeiro: Imago.

Pereira, E. S. (1997). Organizações sociais, instituições federais de ensino superior e autonomia universitária. Revista do Serviço Público, ano 48, n. 2, maio-ago. 1997, pp. 58-80.

Rauber, M. J. \& Rauber, A. S. (2013). Perguntar não ofende... Uma abordagem de coaching para o profissional de Secretariado (1a ed.). Toledo, PR: Mundo Hispânico.

Sabino, R. F. \& Rocha, F. G. (2004). Secretariado: Do escriba ao web writer (1a ed.). Rio de Janeiro: Brasport.

Santos, C. S. dos (2006). Introdução à gestão pública. São Paulo: Saraiva.

Silva, N. D. V. \& Kassouf, A. L. (2000). A exclusão social dos jovens no mercado de trabalho brasileiro. São Paulo: Edusp.

Sobral, D. T. (2003). Motivação do aprendiz de Medicina: uso da escala de motivação acadêmica. Psicologia: Teoria e Pesquisa, Brasília, vol. 19, n. 1, pp. 25-31, jan./abr. 2003.

Tadin, A. P.; Rodrigues, J. A. E.; Dalsoquio, P; Guabiraba, Z. R.; \& Miranda, I. T. P. (2005). O conceito de motivação na teoria das Relações Humanas. Maringa Management: Revista de Ciências Empresariais, vol. 2, n.1, pp. 40-47, jan./jun. 2005.

Revista de Gestão e Secretariado - GeSec, São Paulo, v. 6, n. 1, p 48-73, jan./abr. 2015. 
Os fatores que influenciam os egressos do curso de Secretariado Executivo Trilíngue da Universidade Federal de Viçosa a ingressarem no serviço público

UFV (n.d.). Secretariado Executivo Trilíngue. Recuperado de $\underline{\text { http://www.secretariadoexecutivo.ufv.br }}$

Witter, P. G, \& Lomônaco, J. F. B. (1984). Psicologia da aprendizagem (9a ed.). São Paulo: EPU.

Revista de Gestão e Secretariado - GeSec, São Paulo, v. 6, n. 1, p 48-73, jan./abr. 2015. 